\title{
PELATIHAN PEMBELAJARAN AKTIF BERBANTUAN "BLOK ALJABAR" BAGI GURU SMP N 1 PONDOK KELAPA
}

\section{THE TRAINING OF ACTIVE LEARNING BY USING "BLOCK OF ALGEBRA" FOR HIGH SCHOOL TEACHER IN SMP N 1 PONDOK KELAPA}

\author{
Oleh: \\ Nurul Astuty Yensy \\ Program Studi Pendidikan Matematika, FKIP, Universitas Bengkulu \\ Email: nurulastutyyensy@yahoo.com
}

\begin{abstract}
The majority of teacher in SMP N 1 Pondok Kelapa Central Bengkulu still have difficulty how to organize the effective learning. Very rarely do they plan mathematic learning with a real-life approach that enable the student, because they assume that such learning was useless, confusing and time-consuming. Based on the preliminary survey found that in SMP N 1 Pondok Kelapa, the teacher in there still used a conventional method in learning. The teacher rarely used the prop as learning media, as in the matter of quadratic equation. Whereas making innovative and creative mathematical tool was so easy to be created, so that in this activity have done "The training of active learning by using block of algebra for teacher of high school in SMP N 1 Pondok Kelapa. Block of Algebra was a learning tool of matter of quadratic equation. The method used in this activity include: workshop, demonstration, discussion, and Monitoring and Evaluation. Before the activity was done, All of teacher did not have knowledge how to make prop "algebra block". After the workshop was conducted and after completing the practice of making the prop in school, about $84 \%$ (5 groups from 6 groups of teacher) produced better and applicable prop. While the other group had not finished completing the "algebra block" prop because of technical error, but in general (about 95\%) the teacher' response to this activity was excellent and their knowledge of the making of algebra block prop increased.
\end{abstract}

Keywords: Block of Algebra, active learning

\section{PENDAHULUAN}

Matematika merupakan disiplin ilmu yang mempunyai sifat khas bila dibandingkan dengan ilmu yang lain. Secara singkat dikatakan bahwa matematika berkenaan dengan ideide/konsep-konsep abstrak yang tersusun secara hierarkis dan penalarannya deduktif. Depdiknas (2010) menyatakan selain bersifat hierarkis, matematika juga merupakan ilmu yang berpola pikir deduktif dan konsisten. Menurut Rohayati (2012) hingga saat ini, mata pelajaran matematika di sekolah masih dianggap sebagai mata pelajaran yang paling sulit di antara mata pelajaran yang lain, sehingga bantuan alat peraga masih sangat dibutuhkan.

Alat peraga matematika adalah sebuah atau seperangkat benda konkrit yang dibuat, dirancang, dihimpun atau disusun secara sengaja, yang digunakan untuk membantu menanamkan atau mengembangkan konsep-konsep atau prinsip-prinsip dalam matematika. Dengan alat peraga, maka hal-hal yang abstrak dapat disajikan dalam bentuk model-model, 
sehingga siswa dapat memanipulasi objek tersebut dengan cara dilihat, dipegang, diraba, diputarbalikkan, agar lebih mudah memahami matematika. Alat peraga memiliki arti penting dalam pembelajaran matematika dikarenakan sifat matematika yang berhubungan dengan abstraksi.

Selain itu, efektifitas tidaknya suatu kegiatan belajar mengajar di kelas juga tergantung dari strategi pembelajaran yang diterapkan oleh guru, sehingga salah satu tugas guru adalah bagaimana menyelenggarakan pembelajaran efektif sehingga lebih bervariasi, menarik dan menyenangkan. Namun kenyataan di lapangan menunjukkan sebagian besar guru masih mengalami kesulitan bagaimana menyelenggarakan pembelajaran yang efektif. Sangat jarang dijumpai guru merencanakan pembelajaran matematika dengan pendekatan nyata yang mengaktifkan siswa, karena mereka menganggap bahwa pembelajaran yang demikian tidak bermanfaat, membingungkan dan menyita banyak waktu. Di samping itu, kenyataan menunjukkan bahwa bekal kemampuan materi matematika dari para guru (termasuk guru SMP) masih kurang memadai.

Kesulitan dalam menyelenggarakan pembelajaran matematika tersebut juga dialami oleh guru-guru SMP di Kabupaten Bengkulu Tengah khususnya Kecamatan Pondok Kelapa. Kecamatan ini merupakan salah satu diantara 10 kecamatan yang ada di Benteng, dengan jumlah desa dominan lebih banyak (20 desa). Diantara desa tersebut adalah Desa Pondok Kelapa. Berdasarkan survei awal ditemukan bahwa di SMP N 1 Pondok Kelapa, pembelajaran yang diselenggarakan oleh guru-guru matematika masih bersifat konvensional yaitu metode ceramah. Guru masih mengalami kesulitan dalam mentransfer konsep matematika yang bersifat abstrak kepada siswa khususnya materi aljabar. Aspekaspek aljabar belum atau tidak didemonstrasikan dengan alat peraga yang memberikan model konkrit, model visual dan model geometri, sehingga siswa sulit menangkap makna simbol-simbol yang dipelajari pada materi aljabar, khususnya pada persamaan kuadrat. Hal ini terlihat dari sekitar $50 \%$ siswa kelas IX masih keliru dalam memahami konsep persamaan kuadrat ini. Selain itu, media pembelajaran seperti alat peraga matematika relatif masih kurang memadai, apalagi alat peraga untuk menanamkan konsep persamaan kuadrat sama sekali belum ada. Hal ini berdampak juga pada motivasi belajar siswa yang rendah dan siswa kurang aktif, sehingga secara tidak langsung menunjukkan pembelajaran yang terjadi tidak efektif dan kurang menyenangkan.

Selanjutnya, jumlah guru di SMP N 1 Pondok Kelapa cukup banyak, yaitu 35 orang dan sekolah tersebut merupakan salah satu SMP pavorit di Kecamatan Pondok Kelapa . Berdasarkan wawancara dengan salah seorang guru kelas IX SMP N 1 Pondok Kelapa yang mengajarkan matematika materi tentang persamaan kuadrat mengatakan bahwa mayoritas guru matematika mengalami kesulitan dalam mengajarkan matematika kepada siswa. Hal ini karena mereka kurang menguasai bagaimana mengajarkan konsep matematika agar terlihat lebih konkrit. Biasanya mereka lebih banyak memberikan rumusrumus matematika, contoh soal dan latihan kepada siswa. Khusus materi persamaan kuadrat, mereka sama sekali belum berpengalaman menggunakan media pembelajaran atau alat peraga sebagai alat bantu pembelajaran.

Permasalahan selanjutnya yaitu tidak semua guru-guru di sekolah mampu membuat atau merancang alat peraga pembelajaran sebagai alat bantu di sekolah agar siswa menjadi lebih aktif, karena memang dalam pelaksanaannya tidak mudah, dan membutuhkan pemikiran inovatif dan kreatif serta waktu yang cukup lama, sehingga dalam kegiatan ini dilakukan sosialisasi dan pelatihan pembelajaran aktif berbantuan "Blok Aljabar" bagi guru SMP N 1 Pondok Kelapa. Blok Aljabar merupakan nama alat peraga untuk memahami konsep persamaan kuadrat (materi SMP Kelas IX). 
Cara pembuatan Blok Aljabar tersebut adalah sebagai berikut:

1. Siapkan alat-alat seperti gergaji gabus, gunting, silet, mistar, pensil, lem dan solatif serta bahan-bahan meliputi spon warna dan kertas manila warna, selanjutnya warna yang digunakan cukup 3 warna, misalnya warna merah, hijau dan kuning.

2. Potong gabus (spon warna) dengan ukuran masing-masing warna sebagai berikut: a) warna merah $7 \mathrm{~cm}$ x $7 \mathrm{~cm}$ sebanyak 5 buah (baris pertama), b) Warna hijau $7 \mathrm{~cm} \times 2,5$ cm sebanyak 15 buah (baris kedua) dan c) warna kuning 2,5 cm x 2,5 cm sebanyak 15 buah (baris ketiga). Selanjutnya kertas manila warna yang bersesuaian dengan warna spon tersebut juga dipotong seperti ukuran pada spon. Tempelkan kertas tersebut pada spon sesuai warna masing-masing.

3. Ambil papan sebagai media untuk tempat menempelkan gabus-gabus tersebut, sehingga gabus- gabus itu dapat diotak-atik sesuai kebutuhan. Secara lengkap lihat gambar 1 berikut:

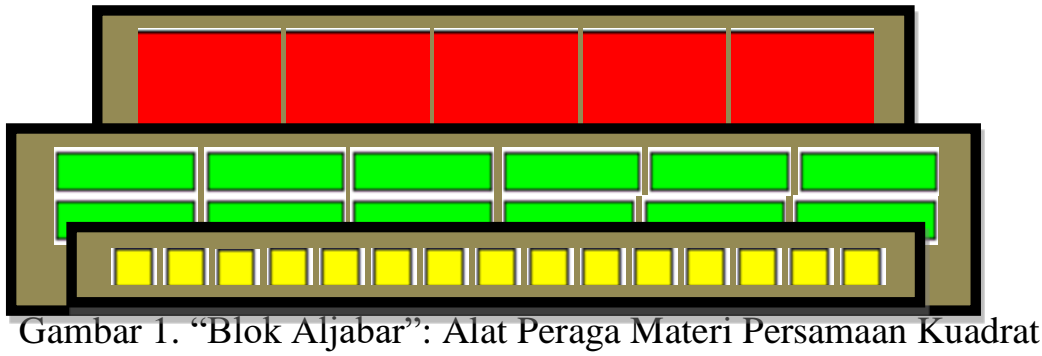

Kegiatan ini bertujuan untuk memberikan pengetahuan kepada guru SMP N 1 Pondok Kelapa tentang pembelajaran aktif berbantuan alat peraga"Blok Aljabar" serta teknik pembuatannya. Selain itu juga untuk memotivasi mereka agar dapat menciptakan media pembelajaran matematika yang inovatif dan kreatif bagi siswa.

Kegiatan ini diharapkan memberikan manfaat bagi guru-guru di SMP N 1 Pondok Kelapa sehingga mereka:

a. Memiliki pengetahuan tentang pembelajaran aktif berbantuan alat peraga "Blok Aljabar".

b. Memiliki kemampuan membuat alat peraga "Blok Aljabar".

c. Memiliki motivasi yang tinggi untuk membuat alat peraga matematika yang inovatif dan kreatif.

\section{METODE PENGABDIAN}

Metode pelaksanaan pengabdian yang dilakukan adalah sebagai berikut:

1. Metode ceramah

Metode ini digunakan untuk memberikan pengetahuan kepada guru-guru SMP N 1 Pondok Kelapa tentang berbagai pembelajaran aktif matematika, salah satunya dengan menggunakan alat peraga "Blok Aljabar".

2. Metode Demonstrasi

Metode demonstrasi pada kegiatan ini menjelaskan langsung disertai praktek kepada guru-guru SMP N 1 Pondok Kelapa tentang bagaimana cara penggunaan Blok Aljabar serta cara pembuatannya.

3. Pengerjaan Tugas Terbimbing

Metode ini digunakan untuk mengetahui sejauh mana pemahaman guru-guru SMP tentang pembuatan dan penggunaan Blok Aljabar. Para peserta (guru-guru) ditugaskan secara kelompok untuk membuat alat peraga Blok Aljabar. 
4. Metode Diskusi dan Tanya Jawab

Metode diskusi dan tanya jawab dilakukan sebagai bentuk interaksi antara peserta dan instruktur. Metode ini bertujuan untuk membantu peserta dalam pembuatan Blok Aljabar serta penggunaannya dalam pembelajaran matematika. Diskusi dan tanya jawab berlangsung selama kegiatan seminar, demonstrasi dan penugasan. Metode diskusi juga digunakan untuk memberikan kesempatan kepada peserta pelatihan untuk mendalami, mengembangkan, dan menyamakan persepsi tentang alat peraga matematika (Blok Aljabar) dan penerapannya dalam pembelajaran matematika khususnya materi persamaan kuadrat.

5. Monitoring dan Evaluasi

Metode monitoring digunakan untuk mengetahui apakah peserta pelatihan menerapkan pengetahuan dan keterampilan tentang pembelajaran aktif berbantuan blok aljabar di sekolah setelah mereka mengikuti kegiatan pelatihan ini.

Selama berlangsungnya kegiatan pelatihan dilakukan kegiatan pengamatan dengan menggunakan pedoman pengamatan, yaitu untuk mengetahui apakah kegiatan pelatihan berlangsung sesuai dengan rencana dan untuk mengetahui respon peserta terhadap kegiatan pelatihan.

Kegiatan pelatihan ini dikatakan berhasil, jika terjadi perubahan tingkah laku peserta pelatihan dari segi pengetahuan dan keterampilan tentang pembelajaran aktif berbantuan blok aljabar yang ditandai dengan:

a. Kemampuan peserta pelatihan menyampaikan penggunaan alat peraga "Blok Aljabar" kepada siswa, yang ditandai dengan meningkatnya pemahaman siswa tentang konsep persamaan kuadrat.

b. Kemampuan peserta pelatihan dalam membuat alat peraga "Blok Aljabar", yang ditandai dengan adanya sebuah alat peraga "Blok Aljabar" yang sudah jadi dibuat oleh setiap kelompok.

c. Respon peserta terhadap kegiatan pelatihan ini adalah baik (peserta yang memberikan respon positif $\geq 80 \%$ ).

Peserta pelatihan terdiri dari guru-guru matematika di SMP N 1 Pondok Kelapa, Kecamatan Pondok Kelapa Kabupaten Bengkulu Tengah. SMP ini terletak yaitu lebih kurang $7 \mathrm{~km}$ dari lokasi UNIB.

\section{HASIL DAN PEMBAHASAN}

Pengetahuan guru-guru SMP tentang pembelajaran aktif (active learnig) rata-rata relatif kurang (95\%), dan hanya 2 orang guru (5\%) yang pernah mencoba menerapkan active learnig matematika di sekolah mereka dan itupun hanya bisa diterapkan untuk mata pelajaran Bahasa Indonesia dan Biologi saja. Para guru belum banyak mengetahui proses pembelajaran yang baik diterapkan ke siswa. Misalnya sangat jarang para guru memanfaatkan media/alat peraga pembelajaran serta lebih dominan menggunakan metode pembelajaran satu arah (konvensioanal), yaitu masih berpusat pada guru (teacher's center). Menurut Suparman (1997) bahwa strategi pembelajaran mengandung empat komponen utama, yaitu: urutan kegiatan pembelajaran, metode pembelajaran, media pembelajaran, dan waktu yang digunakan dalam proses pembelajaran. Oleh karena itu, untuk dapat merencanakan dan melaksanakan kegiatan pembelajaran yang sebaik-baiknya tentulah sangat tergantung dari strategi yang akan dipilih guru untuk digunakan dalam pembelajaran. 
Selanjutnya Depdiknas (2005) mengemukakan bahwa pembelajaran aktif merupakan pembelajaran yang membuat atau memberikan peluang pada siswa untuk: (1) aktif bertanya, mengemukakan gagasan dan mempertanyakan gagasan orang lain dan gagasannya; (2) kreatif, yaitu merancang atau membuat sesuatu dan menulis atau mengarang; (3) menguasai keterampilan yang diperlukan; dan (4) senang yang membuat siswa berani mencoba atau berbuat, berani bertanya, berani mengemukakan pendapat dan berani mempertanyakan gagasan orang lain. Sedangkan salah satu ciri pembelajaran aktif yaitu guru menggunakan berbagai alat bantu dan berbagai cara dalam membangkitkan semangat, termasuk menggunakan lingkungan sebagai sumber belajar untuk menjadikan pembelajaran menarik, menyenangkan dan cocok bagi siswa.

Berdasarkan hasil angket yang disebarkan ke guru-guru dalam kegiatan ini diperoleh bahwa hampir 100\% guru-guru SMP N 1 Pondok Kelapa Kecamatan Pondok Kelapa Kabupaten Bengkulu Tengah tidak menggunakan alat peraga/media bantu dalam mata pelajaran matematika. Pada pembelajaran matematika, media pembelajaran sebagai alat bantu sesuai dengan fungsinya dapat dikelompokkan menjadi dua, yaitu alat peraga dan sarana. Sebagai alat peraga, media pengajaran itu membantu siswa memahami konsep matematika dalam wujud yang konkrit. Sedangkan yang masuk dalam kelompok sarana berfungsi membantu terjadinya proses belajar siswa (Estiningsih, 1994).

Dalam kegiatan belajar mengajar (KBM) matematika, alat peraga berperan membantu siswa menguasai pengetahuan tentang konsep matematika yang dipelajari dalam KBM. Sebagai contoh: kotak kapur, kotak kue sebagai model geometri ruang berfungsi sebagai alat peraga apabila digunakan untuk mengajarkan konsep bangun ruang balok. Sarana berperan membantu proses belajar siswa dalam KBM untuk pembinaan keterampilan maupun untuk pemahaman konsep. Sebagai contoh tabel perkalian dua bilangan satu angka yang pengisiannya digunakan untuk beradu cepat di antara siswa merupakan kegiatan untuk membina keterampilan siswa dalam fakta perkalian dasar. Pada kesempatan lain tabel perkalian dapat digunakan dalam KBM untuk pemahaman konsep yaitu membantu siswa menemukan sifat pertukaran tempat yang dimiliki operasi hitung perkalian. Keterkaitan antara alat peraga dan kegiatan belajar untuk penanaman konsep menunjukkan bahwa macam alat peraga sesuai dengan ragam materi matematika yang dipelajari siswa dan yang tergolong sebagai pengertian baru atau pengertian dasar.

Alat peraga merupakan salah satu dari media pendidikan adalah alat untuk membantu proses belajar mengajar agar proses komunikasi dapat berhasil dengan baik dan efektif. Hal ini sesuai dengan pendapat Amir Hamzah (dalam Herlina, 2005) bahwa "media pendidikan adalah alat-alat yang dapat dilihat dan didengar untuk membuat cara berkomunikasi menjadi efektif”. Sedangkan yang dimaksud dengan alat peraga menurut Nasution (dalam Herlina, 2005) adalah "alat bantu dalam mengajar biar lebih efektif". Salah satu alat peraga dalam mata pelajaran matematika SMP adalah "Blok Aljabar", yakni alat peraga yang terdiri dari beberapa blok sesuai dengan pangkat dari variabel yang diketahui pada materi persamaan kuadrat khususnya dalam pemfaktoran.

"Blok Aljabar" merupakan alat peraga yang dibuat sendiri untuk menanamkan konsep tentang pemfaktoran dalam persamaan kuadrat yaitu salah satu materi matematika yang mulai dipelajari di kelas VII SMP. 

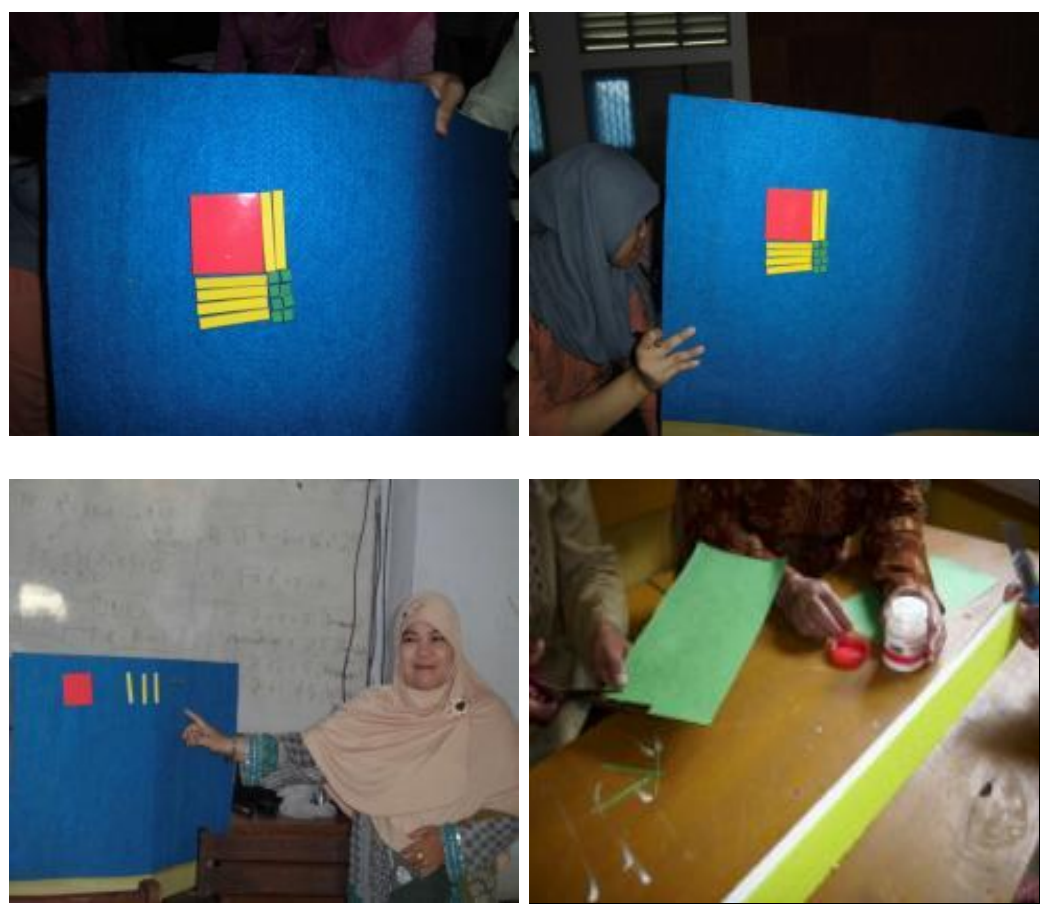

Gambar 2. Demonstrasi penggunaan dan pembuatan alat peraga Blok Aljabar

Guru-guru SMP N 1 Pondok kelapa Kabupaten Bengkulu Tengah pada awalnya sebanyak $100 \%$ belum memiliki pengetahuan bagaimana cara pembuatan alat peraga "Blok Aljabar" dalam mata pelajaran matematika khususnya di SMP. Setelah workshop/ seminar dilaksanakan dan setelah selesai kegiatan praktek pembuatan alat peraga ini di sekolah, maka sekitar 84\% (5 kelompok dari 6 kelompok guru) yang menghasilkan alat peraga yang lebih baik dan dapat diterapkan. Sedangkan 1 kelompok lagi belum tuntas menyelesaikan alat peraga "Blok Aljabar" dikarenakan kesalahan teknis, namun secara umum (sekitar 95\%) respon guru terhadap kegiatan ini sangat baik (positif) dan pengetahuan mereka tentang Active Learning matematika SMP menjadi lebih meningkat.

\section{Cara kerja alat peraga "Blok Aljabar"}

Alat peraga ini digunakan dengan cara menyusunnya sesuai dengan simbol pada aljabar, kemudian diotak-atik dan dipindah-pindah untuk memahami simbol-simbol dan mencari penyelesaian pada pelajaran persamaan kuadrat.

Contoh penerapan:

\section{Menyusun Blok-Blok Sesuai Simbol dalam Aljabar}

\section{Contoh:}

Diberikan bentuk aljabar sebagai berikut: $2 \mathrm{x}^{2}+3 x+5$. Kemudian dapat disusun blok-blok yang sesuai, misalnya sebagai berikut:
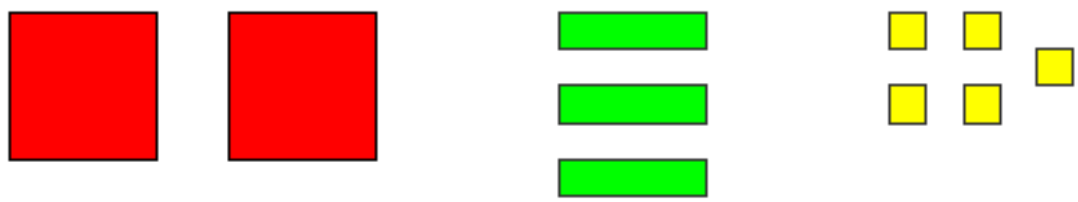

Atau sebaliknya misalkan diberikan suatu susunan blok-blok, kemudian dicari bentuk aljabar yang dapat diwakili atau dimodelkannya. 


\section{Memfaktorkan}

Dalam aljabar memfaktorkan berarti menyatakan suatu bentuk aljabar ke dalam perkalian dua bentuk aljabar. Dalam geometri luas daerah suatu persegi panjang merupakan hasilkali panjang dan lebar yang dapat dikatakan juga merupakan perkalian dari dua bilangan, sehingga dapat dikatakan memfaktorkan adalah menguraikan luas persegi panjang ke dalam panjang dan lebarnya.

Contoh:

Diberikan bentuk aljabar $x^{2}+3 x+2$. Susunan blok yang sesuai adalah sebagai berikut:

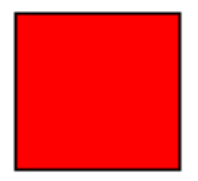

$x^{2}$

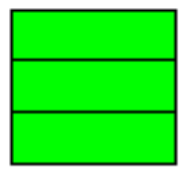

$3 x$

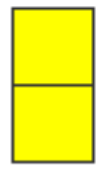

2

Untuk mencari faktor dari bentuk aljabar (bentuk kuadrat) di atas adalah dengan cara menyusun blok-blok tersebut menjadi sebuah bangun datar (persegi atau persegi panjang). Dari blok-blok dalam susunan di atas dapat diperoleh bentuk geometri sebagai berikut:

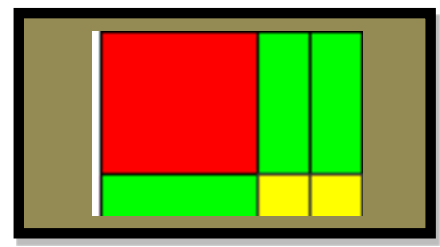

Berdasarkan susunan bentuk ini dapat diperoleh faktor dari $x^{2}+3 x+2$ dengan cara mencari panjang dan lebar persegi panjang yang terbentuk. Dari persegi panjang di atas terlihat panjangnya adalah $x$ ditambah 2 satuan, ditulis $(x+2)$ dan lebarnya adalah $x$ ditambah 1 satuan, ditulis $(\mathrm{x}+1)$.

Jadi faktor dari bentuk $x 2+3 x+2$ adalah $(x+2)(x+1)$.

\section{KESIMPULAN DAN SARAN}

\section{Kesimpulan}

1. Pengetahuan guru-guru SMP N 1 Pondok Kelapa Kecamatan Pondok Kelapa Kabupaten Bengkulu Tengah tentang Active Learning Matematika relatif kurang yaitu hanya sekitar 5\% yang mengetahui tentang Active Learning matematika SMP.

2. Kemampuan dan keterampilan guru-guru SMP di Kecamatan Pondok Kelapa Kabupaten Benteng dalam membuat alat peraga "Blok Aljabar" tergolong baik (sekitar 84\%) kelompok peserta pelatihan menghasilkan alat peraga ini dengan hasil baik dan bisa diterapkan pada mata pelajaran matematika SMP.

3. Motivasi guru mengikuti pelatihan ini tergolong baik (respon positif peserta pada angket sebesar 95\%). 


\section{Saran}

Berdasarkan hasil kegiatan pelatihan, maka disarankan kepada pihak-pihak yang terkait dan berkepentingan dengan masalah pembelajaran matematika, yaitu sebagai berikut:

1. Perlu dilakukan sosialisasi maupun pelatihan tentang Active Learning Matematika kepada para guru maupun siswa pada jenjang SMA.

2. Institusi pendidikan, baik SD, SMP, maupun SMA perlu menyusun Rencana Pembelajaran yang berorientasi Active Learning khususnya mata pelajaran matematika yang bersifat abstrak.

\section{DAFTAR PUSTAKA}

Depdiknas, 2005, Contoh Model PAKEM Matematika, Dirjen Pendidikan Dasar dan Menengah. PPPG Matematika: Yogyakarta.

Depdiknas, 2010, Pedoman Pembelajaran Matematika di Sekolah Dasar, Direktorat Pembinaan Taman Kanak-kanak dan Sekolah Dasar: Jakarta.

Estiningsih, 1994, Penggunaan Alat Peraga dan Media dalam Pembelajaran Matematika, Raja Grafindo Persada: Jakarta.

Herlina, C, 2005, Upaya untuk Menguji Efektifitas Pengajaran dengan Menggunakan Alat Peraga yang akan Dibandingkan dengan Pengajaran Tanpa Menggunakan Alat Peraga, UNNES: Semarang.

Rohayati, A, 2012, Alat Peraga Pembelajaran Matematika, UPI: Bandung.

Suparman, 1997, Strategi Pembelajaran Matematika SMP, Raja Grafindo Persada: Jakarta. 